\title{
Determination of Atropine Sulfate in Human Urines by Capillary Electrophoresis Using Chemical Modified Electrode as Electrochemiluminescence Sensor
}

\author{
Min Zhou, ${ }^{1}$ Juan Mi, ${ }^{1}$ Yujie Li, ${ }^{1}$ Huashan Zhang, $^{2}$ and Yanjun Fang ${ }^{1,2}$ \\ ${ }^{1}$ Key Laboratory of Eco-Environment-Related Polymer Materials, Ministry of Education, Key Laboratory of Polymer Materials of \\ Gansu Province, and College of Chemistry and Chemical Engineering, Northwest Normal University, Lanzhou 730070, China \\ ${ }^{2}$ Institute of Hygienic and Environmental Medicinal Science, Key Laboratory of Risk Assessment and Control for \\ Environment \& Food Safety, Tianjin 300050, China \\ Correspondence should be addressed to Yanjun Fang, yanjunfang1973@163.com
}

Received 10 April 2011; Revised 13 July 2011; Accepted 13 July 2011

Academic Editor: Farnoush Faridbod

Copyright (๑) 2011 Min Zhou et al. This is an open access article distributed under the Creative Commons Attribution License, which permits unrestricted use, distribution, and reproduction in any medium, provided the original work is properly cited.

$\mathrm{A} \mathrm{Ru}(\mathrm{bpy})_{3}{ }^{2+}$-based electrochemiluminescence (ECL) detection coupled with capillary electrophoresis (CE) was developed for the determination of atropine sulfate on the basis of an Eu-PB modified platinum electrode as the working electrode. The analyte was injected to separation capillary of $50 \mathrm{~cm}$ length $(25 \mu \mathrm{m}$ i.d., $360 \mu \mathrm{m}$ o.d.) by electrokinetic injection for $10 \mathrm{~s}$ at $10 \mathrm{kV}$. Parameters related to the separation and detection were discussed and optimized. It was proved that $10 \mathrm{mM}$ phosphate buffer at $\mathrm{pH} 8.0 \mathrm{could}$ achieve the most favorable resolution, and the high sensitivity of detection was obtained by using the detection potential at $1.15 \mathrm{~V}$ and $5 \mathrm{mM} \mathrm{Ru}(\text { bpy })_{3}{ }^{2+}$ in $80 \mathrm{mM}$ phosphate buffer at $\mathrm{pH} 8.0$ in the detection reservoir. Under the optimized conditions, the ECL peak area was in proportion to atropine sulfate concentration in the range from 0.08 to $20 \mu \mathrm{g} \cdot \mathrm{mL}^{-1}$ with a detection limit of $50 \mathrm{ng} \cdot \mathrm{mL}^{-1}(3 \sigma)$. The relative standard derivations of migration time and peak area were 0.81 and $3.19 \%$, respectively. The developed method was successfully applied to determine the levels of atropine sulfate in urine samples of patients with recoveries between 90.9 and $98.6 \%$.

\section{Introduction}

Atropine $(( \pm)$-hyoscyamine $)$ is an active tropine alkaloid from solanaceous plants (as one of a traditional Chinese crude herb), and its chemical structure is shown in Figure 1. Atropine sulfate has been utilized clinically for many years as anticholinergic agent in premedication of anesthesia. However, a high dosage of atropine sulfate can stimulate the central nerve system and disrupt the human renal function leading to toxic reaction [1]. Therefore, it is necessary to establish sensitive and effective methods for the quantitation of atropine sulfate in the field of clinical medicine.

Up to date, different chromatographic methods including liquid chromatography (LC) [2], high-performance liquid chromatography (HPLC) $[3,4]$, thin-layer chromatography (TLC) [5], and gas chromatography (GC) [6] have been reported for the analysis of atropine. However, a drawback of chromatography appears to be time consuming due to necessary extraction, concentration, and/or derivatization prior to the analysis. In addition, a bulk acoustic wave sensor has recently been fabricated and utilized for the determination of atropine sulfate in serum and urine [7]. Of the applied field of spectroscopic analysis, the atomic absorption method (AAS) [8], chemiluminescence method (CL) [9], and the electrochemiluminescence method (ECL) [10] have also been developed for atropine detection. However, these methods often encounter poor selectivity in the assay of complicated samples when coupled with no other separated techniques.

Capillary electrophoresis (CE) represents an interesting alternative as a powerful separation tool and has been applied for atropine analysis already. However, the present CE methods for atropine are usually coupled with UV-V detector, resulting in the restricted detection limits [11]. In recent years, the marriage of $\mathrm{CE}$ to $\mathrm{Ru}(\mathrm{bpy}) 3^{2+}$-based ECL detection has proved to be a promising and efficient 


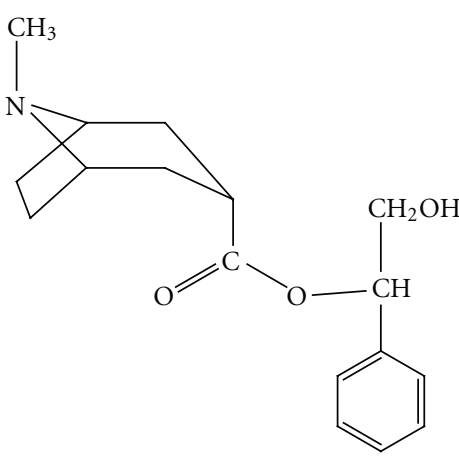

FIgURE 1: Structure of atropine.

analytical technique in the field of biochemical analysis with high sensitivity and excellent separation efficiency [12-15]. However, the utilization of a bare metal platinum electrode in CE-ECL detection can deteriorate stability and sensitivity because of the poisoning effect of complicated matrices in real biological fluids [10].

In recent years, chemical modified electrodes have been widely used for the detection of trace amounts of real biological fluids since the poisoning effect of complex matrixes on the bare platinum electrode could deteriorate the stability and sensitivity [16]. Especially, Prussian Blue (PB), its analogue and related composite film modified electrodes have received more attention in wide range of electrochemistry because of inherent stability, highly reversible nature of the electrode reactions, ease of preparation, and low cost [17]. Unfortunately, the application of a PB analogue modified electrode with rare earth ions in CE-ECL systems has not been reported by other workers although some modified electrodes have also been used as solid-state ECL detectors in CE-ECL detection $[16,18]$. It was proved in our previous works $[19,20]$ that only europium (III)-doped Prussian blue analogue film (Eu-PB) modified platinum microelectrode had good catalytic activity to the electrochemiluminescence of $\mathrm{Ru}(\mathrm{bpy}){ }_{3}{ }^{2+}$-based system. Given this, a platinum electrode modified by Eu-PB is prepared and applied as a working electrode and a $\mathrm{Ru}(\mathrm{bpy}){ }_{3}{ }^{2+}$-based CEECL method is developed for the direct determination of atropine sulfate in urine samples of patients in this paper. By this alternative, a wider linear range and significantly improved sensitivity for atropine sulfate has been obtained since the possible electrode fouling can be avoided.

\section{Experimental}

2.1. Reagents and Chemicals. Atropine sulfate was from Sigma (St. Louis, MO, USA) and freshly prepared by serial dilution with doubly deionized water just before use. Tris (2,2'-bipyridyl) ruthenium (II) chloride hexahydrate (98\%) was from Aldrich (Milwaukee, Wis, USA). Sodium phosphate ( $\mathrm{pH}$ 8.0, G. R.) was used as the buffer solution. All chemicals and reagents were of analytical grade except specific statements. Doubly deionized water was used throughout, and all solutions were filtered through a $0.22 \mu \mathrm{m}$ pore-size membrane before use.
2.2. Apparatus. MPI-A multiparameter chemiluminescence capillary electrophoresis analysis system with self-compiled CE-ECL software (Xi'an Remax Electronic and Technological Co., China) was employed. Uncoated fused silica capillary $(50 \mathrm{~cm} \times 25 \mu \mathrm{m}$ i.d.) was obtained from Yongnian Optical Fiber Factory (Hebei, China). The end-column ECL detection was installed with a three-electrode configuration, which was made up of a Eu-PB modified platinum disk $(\Phi$ $=0.5 \mathrm{~mm}$ ) as a working electrode, an $\mathrm{Ag} / \mathrm{AgCl}$ filled with saturated $\mathrm{KCl}$ as a reference electrode and a platinum wire as an auxiliary electrode.

A CHI832 electrochemical analyzer (Shanghai Chenhua Apparatus Corporation, China) was used for both modification of the working electrode and measurement of the differential pulse voltammograms (D.P.V.s).

2.3. Procedure. The schematic diagram of the CE-ECL detection system was the same as reported in the previous work [19]. A solution of $5 \mathrm{mM} \mathrm{Ru}(\mathrm{bpy})_{3}{ }^{2+}$ in $80 \mathrm{mM}$ phosphate buffer $(\mathrm{pH}$ 8.0) was directly injected into the reaction reservoir. Running buffer solution was $10 \mathrm{mM}$ phosphate buffer ( $\mathrm{pH}$ 8.0). Samples were injected in an electrokinetic mode at $10 \mathrm{kV}$ for $10 \mathrm{~s}$. The separation voltage was $17 \mathrm{kV}$. The photomultiplier tube (PMT) was biased at $-850 \mathrm{~V}$. The capillary-to-working electrode distance was adjusted to about $150 \mu \mathrm{m}$. Fresh Ru(bpy) $3^{2+}$ was replaced every $3 \mathrm{~h}$ in order to obtain good reproducibility. Capillary was rinsed with the running buffer between two sample injections until the baseline was stable. The sample concentrations were quantified by ECL peak area.

\subsection{Preparation of Eu-PB Modified Platinum Electrode.} The modified composite film was prepared on a smooth and cleaning surface of a platinum electrode. A solution of $10.0 \mathrm{~mL} \mathrm{FeCl}_{3}, \quad 10.0 \mathrm{~mL} \mathrm{~K}_{3} \mathrm{Fe}(\mathrm{CN})_{6}, \quad 6.5 \mathrm{~mL} \mathrm{HCl}$, $5.0 \mathrm{mLEuCl}_{3}$, and $5.0 \mathrm{~mL}$ potassium hydrogen phthalate (all concentration were $0.01 \mathrm{M}$ ) was directly added into the electrochemical cell. The Eu-PB film was gradually electrodeposited when cell potential was cyclically scanned from 0 to $1.3 \mathrm{~V}$ at a rate of $20 \mathrm{mV} / \mathrm{s}$ for twenty segments round (versus SCE reference electrode).

2.5. The Urine Sample Preparation. Fresh urine samples of patients were obtained from Lanzhou University Second Hospital and collected from two male patients after $3 \mathrm{~h}$ and $8 \mathrm{~h}$ when $0.5 \mathrm{mg}$ atropine sulfate were injected, respectively. The urine samples were centrifugated at $2000 \mathrm{rpm}$ for $10 \mathrm{~min}$. Then the top layer was separated and diluted 20fold with deionized water, followed by passing through a $0.22 \mu \mathrm{m}$ membrane and being directly injected into the CEECL system and analyzed.

\section{Results and Discussions}

\subsection{Effect of the Eu-PB Modified Platinum Working Electrode}

3.1.1. Effect on Electrooxidation Characterization of $R u(b p y)_{3}{ }^{2+}$. The electrooxidation characterization of $\mathrm{Ru}(\mathrm{bpy}) 3^{2+}$ was tested before and after modification of 


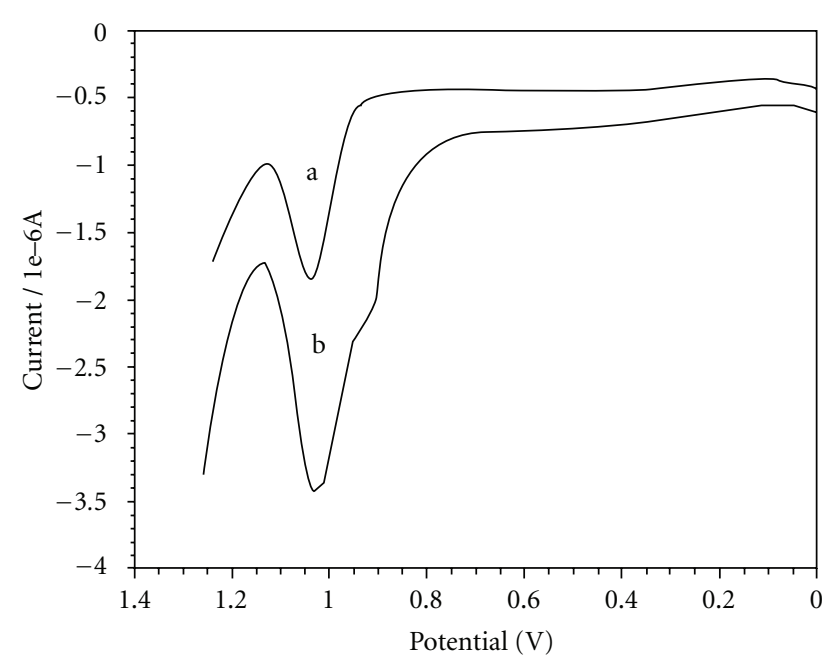

Figure 2: Differential pulse voltammograms of $\mathrm{Ru}(\mathrm{bpy})_{3}{ }^{2+}$ in phosphate buffer ( $\mathrm{pH}$ 8.0): (a) at bare Pt electrode; (b) at Eu-PB modified Pt electrode. Amplitude: $0.05 \mathrm{~V}$; pulse width: $0.05 \mathrm{~s}$; pulse period: 0.2 s. Concentrations: $\mathrm{Ru}(\mathrm{bpy})_{3}{ }^{2+}, 5 \mathrm{mM}$; phosphate buffer, $80 \mathrm{mM}$.

working electrode by differential pulse voltammetry. As shown in Figure 2, the peak current from the electrooxidation of $\mathrm{Ru}(\mathrm{bpy})_{3}{ }^{2+}$ was enhanced significantly at the modified electrode, and the oxidation peak of $\mathrm{Ru}(\mathrm{bpy}) 3^{2+}$ was observed at ca. $1.05 \mathrm{~V}$ (versus $\mathrm{Ag} / \mathrm{AgCl}$ ), with slight negative shift ca. $20 \mathrm{mV}$ with respect to that obtained on the unmodified electrode. Consequently, ECL efficiency of $\mathrm{Ru}(\mathrm{bpy})_{3}{ }^{2+}$ could be improved due to catalytic oxidation of $\mathrm{Ru}(\mathrm{bpy})_{3}{ }^{2+}$ and therefore more production of excited state of $\mathrm{Ru}(\mathrm{bpy})_{3}{ }^{2+}$ in the prepared electrode.

3.1.2. Effect on the ECL Response of Atropine. Luminescence response of atropine was investigated in the prepared electrode as illustrated in Figure 3. It was found that the ratio of the change of ECL signal versus the change of atropine sulfate concentration $(\Delta I / \Delta C)$ was significantly increased by using the Eu-PB modified platinum electrode as ECL sensor, indicating that the change of ECL signal was more sensitive to the change of atropine sulfate concentration. Consequently, the slope of calibration curve would be enhanced. In addition, it was also indicated in Figure 3 that the linear range would be broadened when the Pt electrode was modified. Thus, the prepared electrode would benefit from the improved sensitivity and linearity for atropine sulfate.

3.1.3. Antipoisoning Effect of the Modified Electrode. In order to investigate the Antipoisoning effect of the modified electrode, atropine sulfate in real urine samples of patients were determined by the CE-ECL method using a platinum electrode and the prepared electrode as ECL sensor, respectively. It was found that the use of unmodified electrode led to peak broadening and a considerably unstable measurement due to poisoning effect of electrode, and therefore was unfit for the

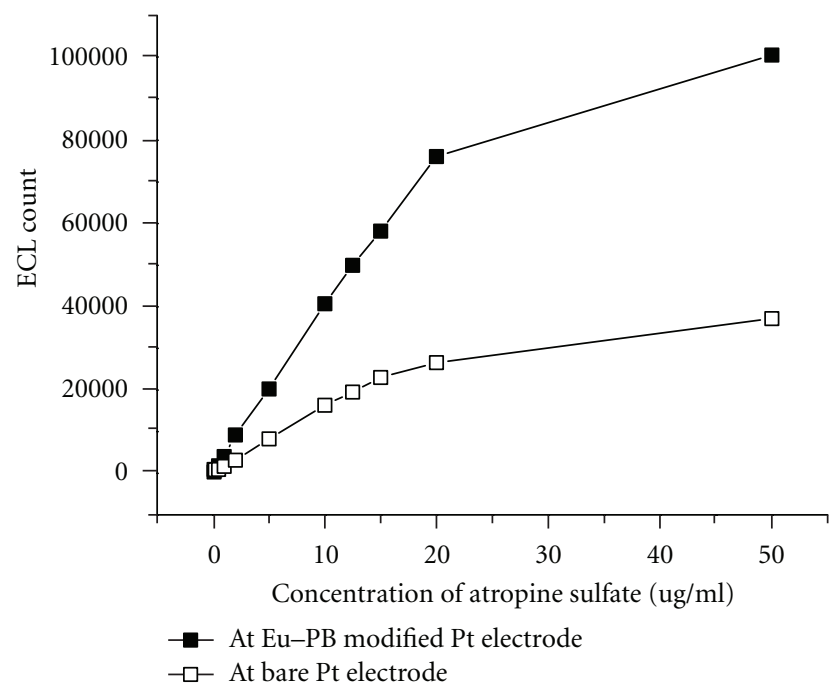

FIGURE 3: Luminescence response of atropine sulfate at bare Pt electrode and at Eu-PB modified electrode: separation capillary: $25 \mu \mathrm{m}$, i.d., $45 \mathrm{~cm}$ length; sample injection: $10 \mathrm{~s}$ at $10 \mathrm{kV}$; separation voltage: $17 \mathrm{kV}$; running buffer: $10 \mathrm{mM}$ sodium phosphate, concentration in detection cell: $80 \mathrm{mM}$, all at $\mathrm{pH}$ 8.0.

assay of real urine samples. While it was found that uric acid, other matrices, and atropine metabolites in urine samples had little interference to the detection by use of the prepared electrode, and consequently the enhanced ECL signal, lower noise, better peak shape, and improved reproducibility were obtained. It was proved as well that the prepared electrode was stable enough for repetitive use in the detection system over one month with no need for electrode replacement. In a word, the modified electrode shows advantage of excellent Antipoisoning effect for real urine samples.

\subsection{Conditions Optimization}

3.2.1. Effect of $R u(b p y)_{3}{ }^{2+}$ Concentration. Concentration of $\mathrm{Ru}(\mathrm{bpy}) 3^{2+}$ had great effect on the ECL signal. The results showed that the ECL intensity increased markedly with increasing $\mathrm{Ru}(\mathrm{bpy})_{3}{ }^{2+}$ concentration from 0.2 to $5.0 \mathrm{mM}$ due to the acceleration of reaction rate. In this work, $5 \mathrm{mMRu}(\text { bpy })_{3}{ }^{2+}$ in $80 \mathrm{mM}$ phosphate buffer was adopted due to concerned oversensitivity and economy in use of reagent.

3.2.2. Effect of Running Buffer. Determination of atropine was studied in different buffer systems including phosphate, acetate, Tris- $\mathrm{HCl}$, citric acid-sodium citrate, and borate buffers. Finally, phosphate was chosen in terms of the stable baseline, lower noise, shorter analysis time, and better peak shape.

Further, $\mathrm{pH}$ effect of phosphate on the detection was investigated in a wide $\mathrm{pH}$ range of 4.5-10.0 at intervals of $0.5 \mathrm{pH}$ units. As indicated in Figure 4, the ECL intensity increased with increase in $\mathrm{pH}$ value in the $\mathrm{pH}$ range $4.5-$ 7.5 and reached a plateau at $\mathrm{pH} 7.5-8.5$, above which it decreased a little. The possible reason was considered as 


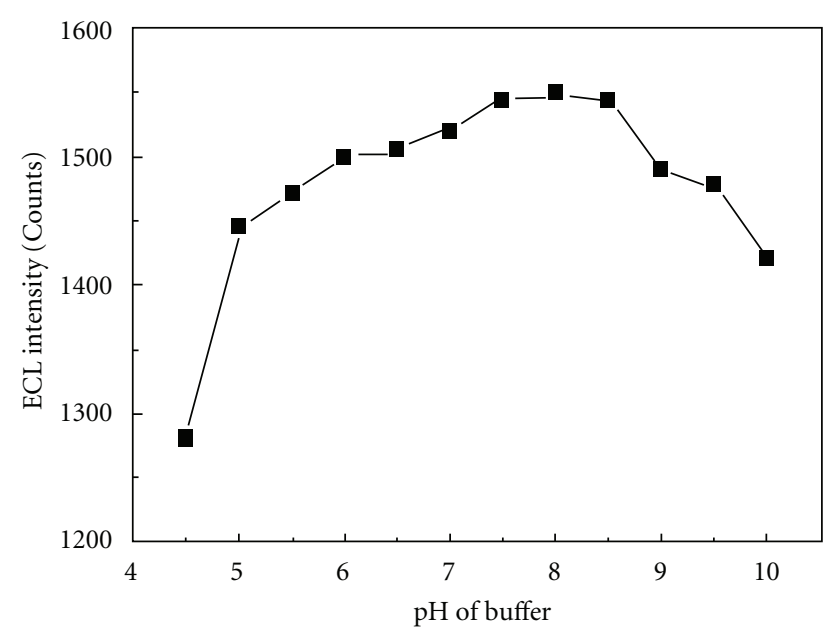

FIGURE 4: pH effect of running buffer on ECL intensity: other conditions, the same as in Figure 3.

the competitive reaction between $\mathrm{Ru}(\mathrm{bpy})_{3}{ }^{2+}$ and $\mathrm{OH}^{-}$ions produced at high $\mathrm{pH}$ value [21]. So $\mathrm{pH} 8.0$ was selected for all the following work.

With fixed $\mathrm{pH}$ value at 8.0 , the concentration of running buffer was changed from 5 to $20 \mathrm{mM}$. It was found that working at high buffer concentration allowed improved sensitivity and resolution. However, high buffer concentration would induce excessive heating caused by Joule effect, resulting in an unstable measurement. Hence, $10 \mathrm{mM}$ phosphate at $\mathrm{pH}$ 8.0 was used as the running buffer.

3.2.3. Effect of Detection Potential. The ECL intensity depends on the efficiency of electroproduced $\mathrm{Ru}(\mathrm{bpy}) 3^{3+}$ and substantially depends on the oxidation potential applied to the electrode. As seen in Figure 5, the increased production of $\mathrm{Ru}(\mathrm{bpy})_{3}{ }^{3+}$ with a rise of potential resulted in an increased response and the highest value was obtained at $1.15 \mathrm{~V}$. Above which, the response slightly diminished, implying that the efficiency of electroproduced $\mathrm{Ru}(\mathrm{bpy}) 3^{3+}$ decreased as competitive reactions involving the buffer dominate. Thus, the optimal potential was $1.15 \mathrm{~V}$.

3.2.4. Effect of Separation Voltage. Separation voltage simultaneously impacted on the ECL intensity and migration time. More analyte arrived in the diffusion layer of working electrode within a given time with the increasing separation voltage, leading to higher ECL signal. Also, increasing separation voltage shortened the migration time because of the increase of EOF. However, the inability of the system to remove excess Joule heat generated at high voltages resulted in peak broadening and a decrease in reproducibility. Finally, the best choice for separation voltage was $17 \mathrm{kV}$.

3.2.5. Effect of Injection Voltage and Injection Time. The effects of injection voltage and injection time were studied as well. The results demonstrated that it was difficult to obtain a favorable ECL intensity though a high column

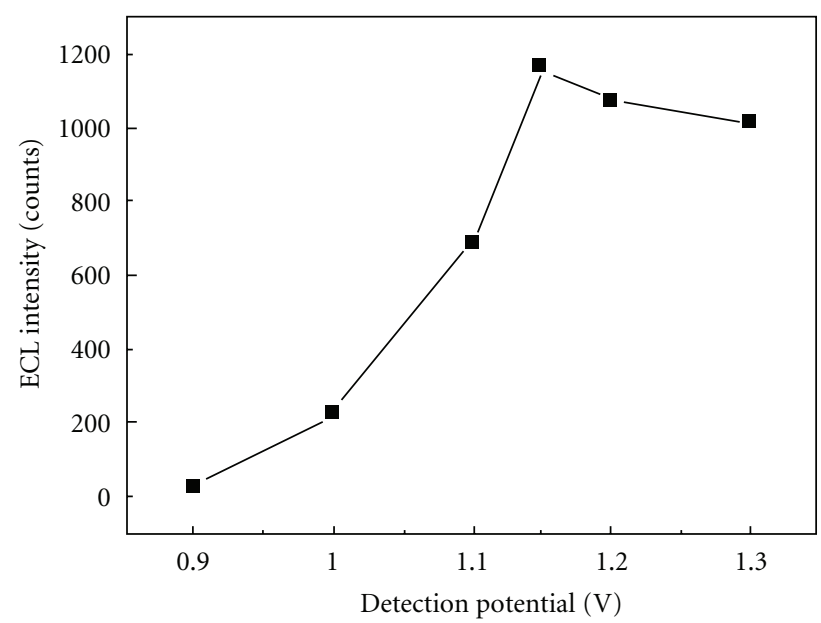

FIGURE 5: Effect of detection potential on ECL intensity: other conditions, the same as in Figure 3.

efficiency could be achieved when the injection time was shortened and the injection voltage was diminished. Also, the reproducibility became worse when an excessive sample volume was introduced. Finally, the injection parameters of $10 \mathrm{~s}$ at $10 \mathrm{kV}$ were recommended.

3.3. Calibration and Detection. Under the optimum conditions, the calibration graph of atropine sulfate concentration versus ECL peak area was linear in the range from 0.08 to $20 \mu \mathrm{g} \cdot \mathrm{mL}^{-1}$, which was wider than that obtained at a bare platinum electrode [22]. The regression equation could be expressed as: $\Delta S=566.26+2256.75 C / \mu \mathrm{g} \mathrm{mL}^{-1}$ with a correlation coefficient of $0.9994(n=8)$. The detection limit, defined as three times the S.D. for the reagent blank signal, was $50 \mathrm{ng} \cdot \mathrm{mL}^{-1}$.

The precision of the proposed method was determined by reduplicate injections $(n=6)$ of $5.0 \mu \mathrm{g} \cdot \mathrm{mL}^{-1}$ atropine sulfate standard solution. The relative standard deviations (R.S.D.) of migration time and ECL peak area were 0.81 and $3.19 \%$, respectively.

3.4. Applications. In order to examine the application for clinic analysis, the levels of atropine sulfate in real urine samples of two patients were determined by the proposed method. The electropherogram in Figure 6 showed that uric acid, other matrices, and atropine metabolites in urine samples had little interference to the detection by use of the prepared electrode. As seen in Figure 6, the peak at $267 \mathrm{~s}$ was identified to be from atropine sulfate by spiking the standards to the sample solution. The quantitative recovery was $98.6 \%$ $(n=5)$, and about $22.4 \%$ atropine sulfate was excreted from urine with unchanged form. In the measurement process, another peak at $375 \mathrm{~s}$ was always detected, which was estimated to be from a normal metabolite in human urine. Similarly, another urinary sample was analyzed as well and the recovery of $90.9 \%(n=5)$ was obtained. The results were listed in Table 1. 


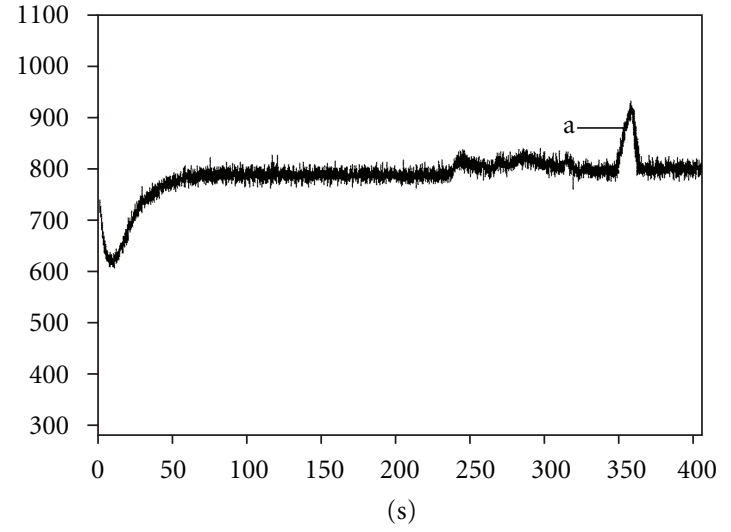

(a)

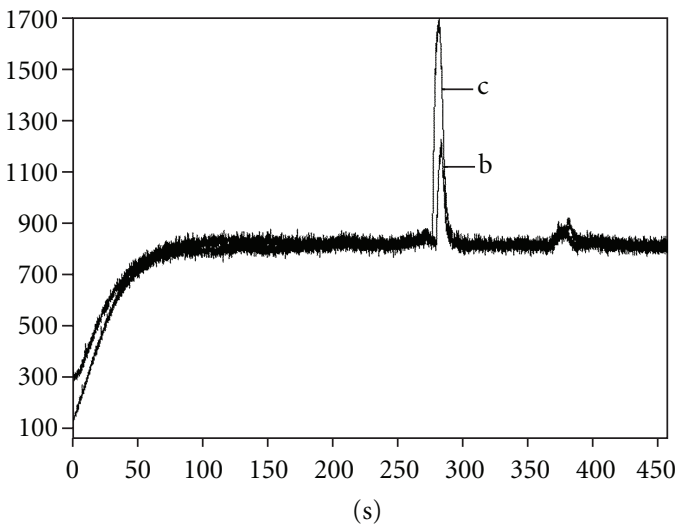

(b)

FIGURE 6: Electropherograms of (a) the diluted urinary sample of a healthy male; (b) the diluted urinary sample of a male patient; (c) the diluted urinary sample of the male patient spiked with $5.0 \mu \mathrm{g} \cdot \mathrm{mL}^{-1}$ atropine sulfate standard solution; other conditions are the same as in Figure 3.

TABLE 1: The determination of atropine sulfate in patient urines $(n=5)$.

\begin{tabular}{lccccc}
\hline Sample & $\begin{array}{c}\text { Found } \\
\left(\mathrm{mg} \cdot \mathrm{mL}^{-1}\right)\end{array}$ & $\begin{array}{c}\text { R.S.D. } \\
(\%) \text { for } \\
\text { peak area }\end{array}$ & $\begin{array}{c}\text { Added } \\
\left(\mathrm{mg} \cdot \mathrm{mL}^{-1}\right)\end{array}$ & $\begin{array}{c}\text { Recovered } \\
\left(\mathrm{mg} \cdot \mathrm{mL}^{-1}\right)\end{array}$ & $\begin{array}{c}\text { Recovery } \\
(\%)\end{array}$ \\
\hline 1 & 0.112 & 1.52 & 0.100 & 0.0986 & 98.6 \\
2 & 0.0782 & 2.19 & 0.100 & 0.0909 & 90.9 \\
\hline
\end{tabular}

Conditions were the same as Table 1. Sample 1 was from the patient who was operated for the polyp excision after ca. $3 \mathrm{~h}$ when atropine sulfate was injected; sample 2 was from the patient who was operated for uremia after ca. $8 \mathrm{~h}$ when atropine sulfate was injected.

\section{Conclusion}

This paper described a $\mathrm{Ru}(\mathrm{bpy})_{3}{ }^{2+}$-based ECL method coupling to $\mathrm{CE}$ technique for the determination of atropine sulfate. An Eu-PB modified platinum electrode was prepared and used as ECL sensor to replace the traditional bare Pt electrode since the adsorption and direct oxidation of electroactive species in real urine samples of patients on the surface of working electrode could be avoided as much as possible. Consequently, the stability and reproducibility in signals, the linear range, and the ratio of ECL signal to atropine sulfate concentration were all significantly improved. To sum up, the proposed method showed an excellent performance with respect to selectivity, sensitivity, linearity, and stability, and further it holds great promise for the determination of tropane alkaloids in body fluids.

\section{Acknowledgments}

The authors are grateful to Natural Foundation (no. 1010RJZA017) of Gansu Province and the Natural Foundation of the National (no. 20707039) for supporting the research.

\section{References}

[1] K. Dost and G. Davidson, "Development of a packedcolumn supercritical fluid chromatography/atmospheric pressure chemical-ionisation mass spectrometric technique for the analysis of atropine," Journal of Biochemical and Biophysical Methods, vol. 43, no. 1-3, pp. 125-134, 2000.

[2] O. Rbeida, B. Christiaens, P. Hubert et al., "Integrated online sample clean-up using cation exchange restricted access sorbent for the LC determination of atropine in human plasma coupled to UV detection," Journal of Pharmaceutical and Biomedical Analysis, vol. 36, no. 5, pp. 947-954, 2005.

[3] M. Nakamura, M. Ono, T. Nakajima, Y. Ito, T. Aketo, and J. Haginaka, "Uniformly sized molecularly imprinted polymer for atropine and its application to the determination of atropine and scopolamine in pharmaceutical preparations containing Scopolia extract," Journal of Pharmaceutical and Biomedical Analysis, vol. 37, no. 2, pp. 231-237, 2005.

[4] R. Sharma, P. K. Gupta, A. Mazumder, D. K. Dubey, K. Ganesan, and R. Vijayaraghavan, "A quantitative NMR protocol for the simultaneous analysis of atropine and obidoxime in parenteral injection devices," Journal of Pharmaceutical and Biomedical Analysis, vol. 49, no. 4, pp. 1092-1096, 2009.

[5] A. P. Gupta, M. M. Gupta, and S. Kumar, "High performance thin layer chromatography of asiaticoside in Centella asiatica," Journal of the Indian Chemical Society, vol. 76, no. 6, pp. 321322, 1999.

[6] J. Pohjola and M. Harpf, "Determination of atropine and obidoxime in automatic injection devices used as antidotes against nerve agent intoxication," Journal of Chromatography A, vol. 686, no. 2, pp. 350-354, 1994.

[7] H. Peng, C. Liang, A. Zhou, Y. Zhang, Q. Xie, and S. Yao, "Development of a new atropine sulfate bulk acoustic wave sensor based on a molecularly imprinted electrosynthesized copolymer of aniline with o-phenylenediamine," Analytica Chimica Acta, vol. 423, no. 2, pp. 221-228, 2000.

[8] M. A. El Ries and S. Khalil, "Indirect atomic absorption determination of atropine, diphenhydramine, tolazoline, and levamisole based on formation of ion-associates with potassium tetraiodometrcurate," Journal of Pharmaceutical and Biomedical Analysis, vol. 25, no. 1, pp. 3-7, 2001. 
[9] P. A. Greenwood, C. Merrin, T. McCreedy, and G. M. Greenway, "Chemiluminescence $\mu$ TAS for the determination of atropine and pethidine," Talanta, vol. 56, no. 3, pp. 539$545,2002$.

[10] Q. Song, G. M. Greenway, and T. McCreedy, "Tris $\left(2,2^{\prime}\right.$ bipyridine)ruthenium(II) electrogenerated chemiluminescence of alkaloid type drugs with solid phase extraction sample preparation," Analyst, vol. 126, no. 1, pp. 37-40, 2001.

[11] Y. Bitar and U. Holzgrabe, "Impurity profiling of atropine sulfate by microemulsion electrokinetic chromatography," Journal of Pharmaceutical and Biomedical Analysis, vol. 44, no. 3, pp. 623-633, 2007.

[12] X.-B. Yin and E. Wang, "Capillary electrophoresis coupling with electrochemiluminescence detection: a review," Analytica Chimica Acta, vol. 533, no. 2, pp. 113-120, 2005.

[13] B. Yuan, C. Zheng, H. Teng, and T. You, "Simultaneous determination of atropine, anisodamine, and scopolamine in plant extract by nonaqueous capillary electrophoresis coupled with electrochemiluminescence and electrochemistry dual detection," Journal of Chromatography A, vol. 1217, no. 1, pp. 171-174, 2010.

[14] F. J. Lara, A. M. García-Campaña, and A. I. Velasco, "Advances and analytical applications in chemiluminescence coupled to capillary electrophoresis," Electrophoresis, vol. 31, no. 12, pp. 1998-2027, 2010.

[15] E. Aehle and B. Dräger, "Tropane alkaloid analysis by chromatographic and electrophoretic techniques: an update," Journal of chromatography B, vol. 878, no. 17-18, pp. 13911406, 2010.

[16] S.-N. Ding, J.-J. Xu, and H.-Y. Chen, "Tris(2,2'-bipyridyl)ruthenium(II)-zirconia-Nafion composite films applied as solid-state electrochemiluminescence detector for capillary electrophoresis," Electrophoresis, vol. 26, no. 9, pp. 1737-1744, 2005.

[17] M. H. Pournaghi-Azar and H. Dastangoo, "Palladized aluminum as a novel substrate for the non-electrolytic preparation of a Prussian Blue film modified electrode," Journal of Electroanalytical Chemistry, vol. 573, no. 2, pp. 355-364, 2004.

[18] W. Cao, J. Jia, X. Yang, S. Dong, and E. Wang, "Capillary electrophoresis with solid-state eletrochemiluminescence detector," Electrophoresis, vol. 23, no. 21, pp. 3692-3698, 2002.

[19] M. Zhou, Y.-J. Ma, X.-N. Ren, X.-Y. Zhou, L. Li, and H. Chen, "Determination of sinomenine in Sinomenium acutum by capillary electrophoresis with electrochemiluminescence detection," Analytica Chimica Acta, vol. 587, no. 1, pp. 104109, 2007.

[20] X. Ren, Y. Ma, M. Zhou, S. Huo, J. Yao, and H. Chen, "Determination of tropane alkaloid components in Przewalskia tangutica Maxim, by capillary electrophoresis with electrochemiluminescence detection," Chinese Journal of Chromatography, vol. 26, no. 2, pp. 223-227, 2008.

[21] J. Liu, W. Cao, X. Yang, and E. Wang, "Determination of diphenhydramine by capillary electrophoresis with tris(2,2' -bipyridyl)ruthenium(II) electrochemiluminescence detection," Talanta, vol. 59, no. 3, pp. 453-459, 2003.

[22] Y. Gao, Y. Tian, and E. Wang, "Simultaneous determination of two active ingredients in Flos daturae by capillary electrophoresis with electrochemiluminescence detection," Analytica Chimica Acta, vol. 545, no. 2, pp. 137-141, 2005. 


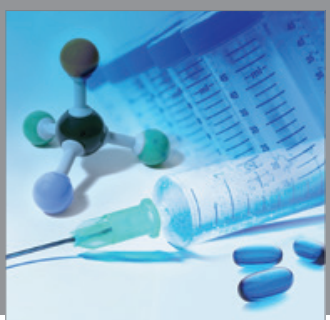

International Journal of

Medicinal Chemistry

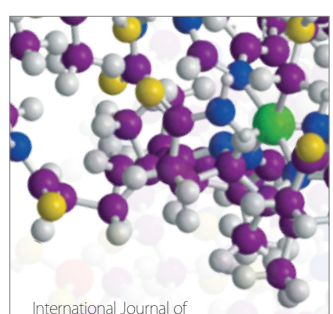

Carbohydrate Chemistry

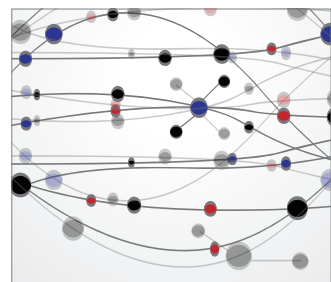

The Scientific World Journal
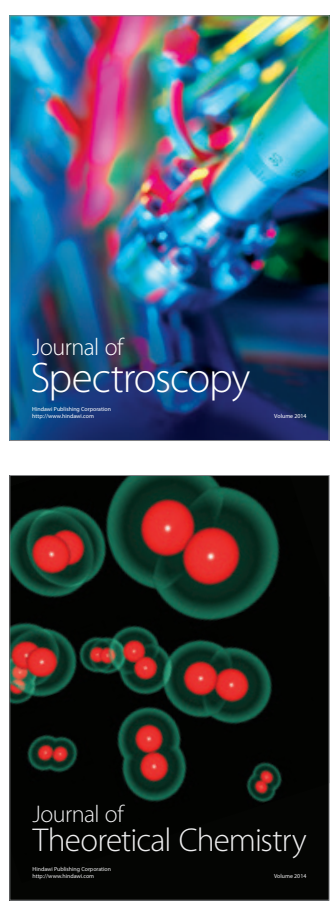
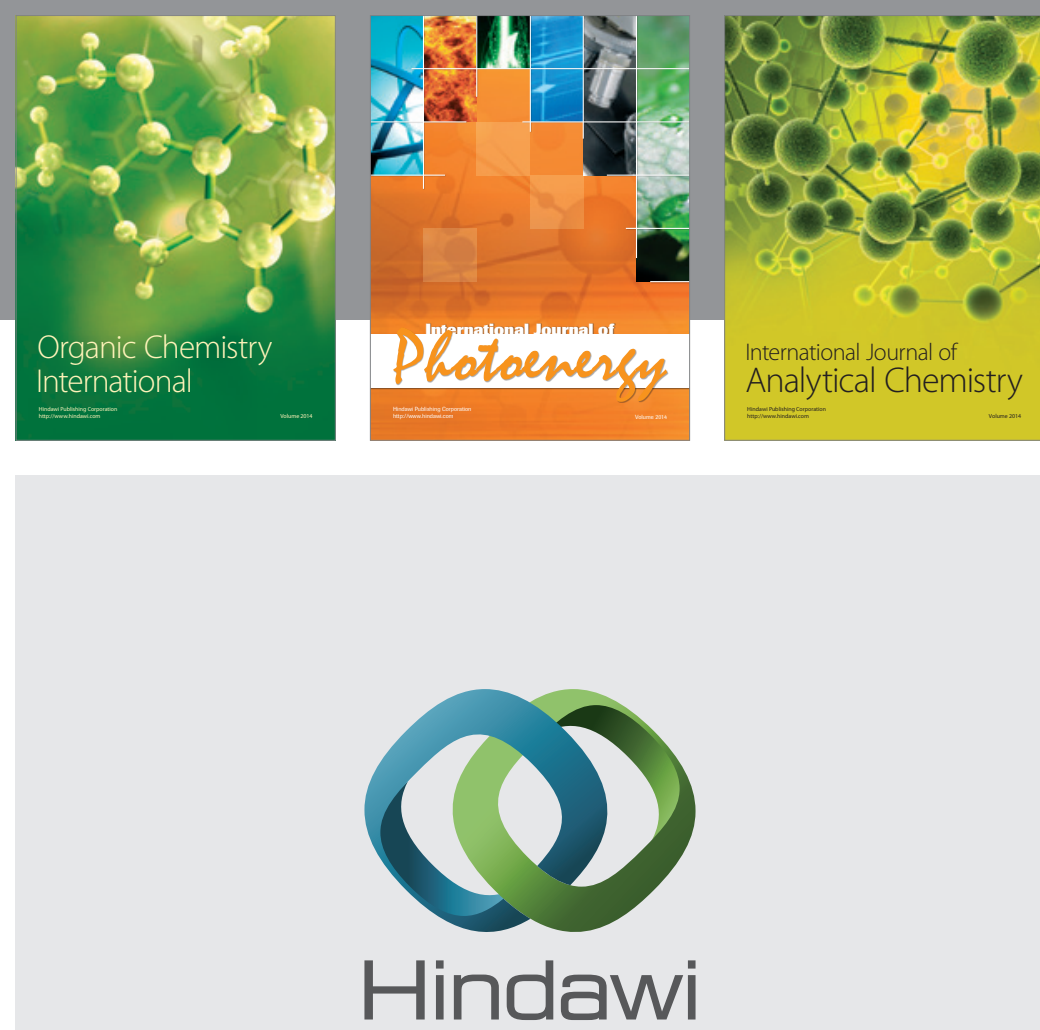

Submit your manuscripts at

http://www.hindawi.com
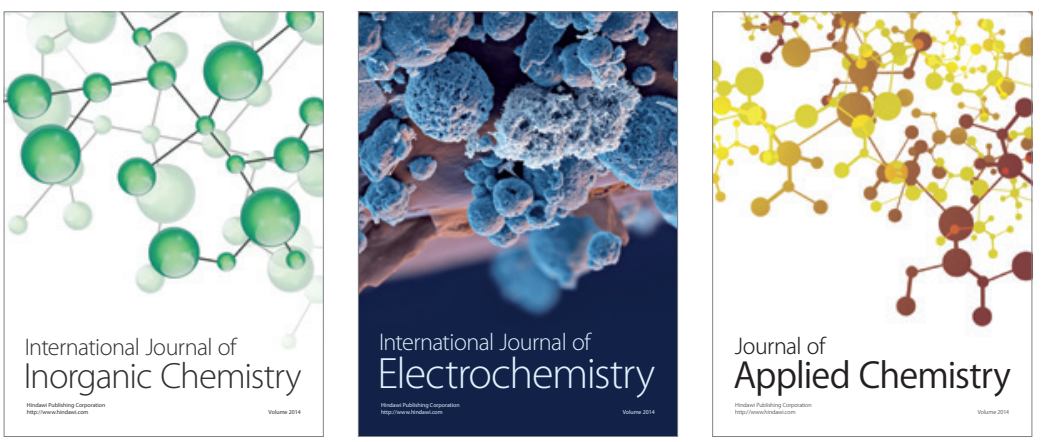

Journal of

Applied Chemistry
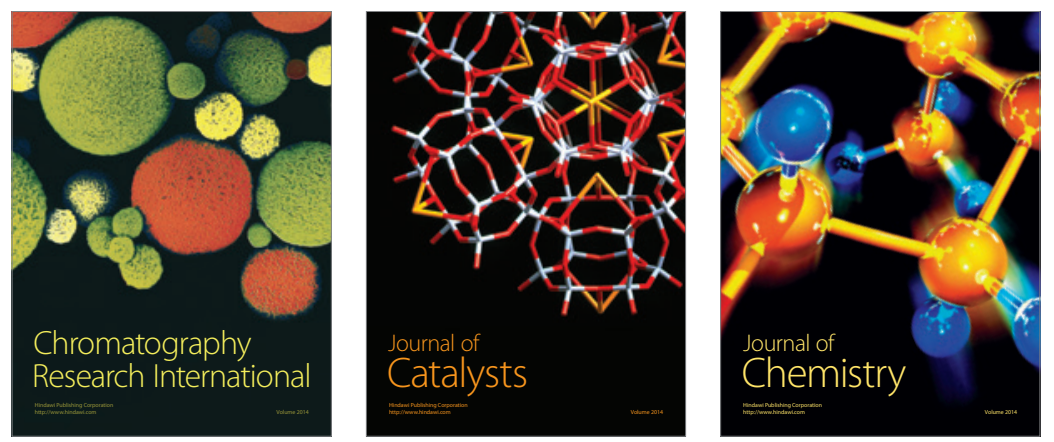
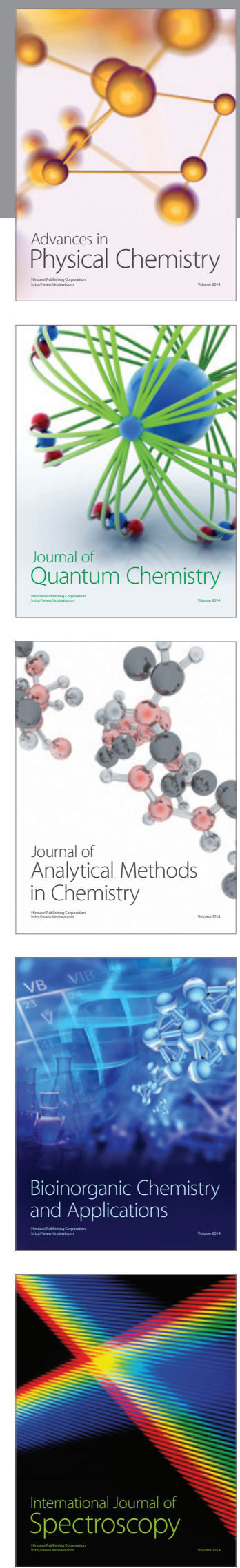